Original Article

\title{
Changes in gluteal pressure and center of force during sitting in children with cerebral palsy
}

\author{
Do Hyun Kim, PT, MS ${ }^{1)}$, Won-Gyu Yoo, PT, $\mathrm{PhD}^{2 *}$, Ji-Hye Do ${ }^{3)}$ \\ 1) HIP\&MAL Laboratory, Department of Rehabilitation Science, Inje University, Republic of Korea \\ 2) Department of Physical Therapy, College of Healthcare Medical Science and Engineering, \\ Inje University: Gimhae, Gyeongsangnam-do, Republic of Korea \\ 3) Department of Occupational Therapy, Kijeon College, Republic of Korea
}

\begin{abstract}
Purpose] The purpose of this study was to measure gluteal pressure and center of force (COF) during sitting in children with cerebral palsy (CP). [Subjects and Methods] The participants were five children with CP and five typically developing controls. We measured peak gluteal pressure and COF using the TekScan system. During the measurements, all children sat on the therapeutic table for 1 minute without back and foot support. [Results] The peak gluteal pressure and COF in children with $\mathrm{CP}$ were significantly higher than values in controls. [Conclusion] This study suggests that it is important to distribute hip pressure evenly and transfer COF in a forward direction during rehabilitation in children with $\mathrm{CP}$.

Key words: Cerebral palsy, Gluteal pressure, Sitting
\end{abstract}

(This article was submitted Aug. 24, 2017, and was accepted Sep. 25, 2017)

\section{INTRODUCTION}

With medical progress, the number of cerebral palsy (CP) patients is increasing globally. Generally, an upright posture during sitting decreases internal disc pressure ${ }^{1)}$. An upright posture results in anterior pelvic tilt, normal lumbar lordotic curve, and a neutral and relaxed thorax ${ }^{1)}$. However, CP patients lack postural stability against gravity, and abnormal posture, such as a hunched trunk and posterior pelvic tilt, are common in children with $\mathrm{CP}^{2)}$. Because most children with $\mathrm{CP}$ have postural problems, they spend more time sitting than standing in daily life ${ }^{3)}$. Prolonged pressure on the surface of the skin can cause obstructions in capillary blood flow, leading to ischemic damage ${ }^{4}$. Therefore, it is important to measure gluteal pressure and center of force (COF) in children with CP. Despite the importance of gluteal pressure and COF in sitting, limited studies have explored these variables in children with CP. Therefore, we measured the peak gluteal pressure and COF during sitting in children with CP.

\section{SUBJECTS AND METHODS}

The participants in this study were five children with CP (age 9.0 \pm 1.2 years, height $128.5 \pm 3.9 \mathrm{~cm}$, weight $27.8 \pm 6.0 \mathrm{~kg}$; three with diplegia, two with hemiplegia) and five age-matched typically developing controls (age $9.4 \pm 0.8$ years, height $138.7 \pm 4.4 \mathrm{~cm}$, weight $34.5 \pm 7.8 \mathrm{~kg}$ ). Ethics approval was obtained from the Inje University Ethics Committee for Human Investigations, and written informed consent was obtained from all participants (2016-05-004). Children with sensory deficits, those who had undergone surgery within the last 6 months, and those who could not sit independently for 5 minutes were excluded from the study. The TekScan system was used to assess peak gluteal pressure and COF. The TekScan software displayed temporal forces, peak gluteal pressures, and COF on a monitor. We then compared the groups with regard to peak

*Corresponding author. Won-Gyu Yoo (E-mail: won7y@inje.ac.kr)

(C2017 The Society of Physical Therapy Science. Published by IPEC Inc.

(c) (1) $\odot$ This is an open-access article distributed under the terms of the Creative Commons Attribution Non-Commercial No DerivaBY NC ND tives (by-nc-nd) License. (CC-BY-NC-ND 4.0: http://creativecommons.org/licenses/by-nc-nd/4.0/) 
gluteal pressure and COF while sitting. During measurement, the children sat on the therapeutic table for 1 minute without back and foot support. All measurements were repeated three times, and the mean value was used for analysis. Approximately 10 -second rest periods were allowed between assessments. The Mann-Whitney U-test was used to determine significant differences between children with CP and controls. PASW Statistics software (ver. 20; Norusis/SPSS, Inc., Chicago, IL, USA) was used for all analyses, and the level of statistical significance was set at $\alpha=0.05$.

\section{RESULTS}

The peak gluteal pressure during sitting in children with CP $\left(0.44 \pm 0.05 \mathrm{~kg} / \mathrm{cm}^{2}\right)$ was significantly higher than that in typically developing children $\left(0.31 \pm 0.06 \mathrm{~kg} / \mathrm{cm}^{2}\right)(\mathrm{p}=0.016)$. Furthermore, the COF during sitting in children with $\mathrm{CP}(12.38 \pm$ $1.26 \mathrm{~cm})$ was significantly higher than that in typically developing children $(8.58 \pm 0.61 \mathrm{~cm})(\mathrm{p}=0.009)$.

\section{DISCUSSION}

The purpose of this study was to investigate peak gluteal pressure and COF during sitting in children with CP. The results showed that values on both measures were significantly higher in children with CP compared with controls $(\mathrm{p}<0.05)$. Lee and Park reported differences in the symmetry index (SI) in children with CP compared with typically developing children. In the present study, the SI value in children with left hemiplegic CP was 4.96 (2.24), whereas that in normal controls was closer to zero $^{5}$. van der Heide et al. explored postural control during reaching in children with $\mathrm{CP}$, and found that children with $\mathrm{CP}$ had reduced trunk extensor muscle activity compared with typically developing children. Furthermore, children with CP showed inappropriate muscle-recruitment patterns ${ }^{6}$. Our study supports the results of these previous studies, suggesting that peak gluteal pressure during sitting may be higher in children with $\mathrm{CP}$ than in controls because uneven weight distribution due to $\mathrm{CP}$ results in higher gluteal pressure. Additionally, in children with $\mathrm{CP}$, the COF during sitting was transferred in a posterior direction compared with typically developing children. This result may reflect decreased sitting balance in children with CP. Overall, our results suggest that it is important to distribute hip pressure evenly and transfer COF in a forward direction during rehabilitation in children with $\mathrm{CP}$.

\section{REFERENCES}

1) Polga DJ, Beaubien BP, Kallemeier PM, et al.: Measurement of in vivo intradiscal pressure in healthy thoracic intervertebral discs. Spine, 2004, 29: 1320-1324. [Medline] [CrossRef]

2) van der Heide JC, Hadders-Algra M: Postural muscle dyscoordination in children with cerebral palsy. Neural Plast, 2005, 12: 197-203, discussion 263-272. [Medline] [CrossRef]

3) Carlberg EB, Hadders-Algra M: Postural dysfunction in children with cerebral palsy: some implications for therapeutic guidance. Neural Plast, 2005, 12: 221-228, discussion 263-272. [Medline] [CrossRef]

4) Bours GJ, De Laat E, Halfens RJ, et al.: Prevalence, risk factors and prevention of pressure ulcers in Dutch intensive care units. Results of a cross-sectional survey. Intensive Care Med, 2001, 27: 1599-1605. [Medline] [CrossRef]

5) Lee IH, Park SY: Abnormal sitting pressures of hemiplegic cerebral palsy children on a school chair. J Phys Ther Sci, 2015, 27: 499-500. [Medline] [CrossRef]

6) van der Heide JC, Begeer C, Fock JM, et al.: Postural control during reaching in preterm children with cerebral palsy. Dev Med Child Neurol, 2004, 46: 253-266. [Medline] [CrossRef] 